\title{
Methane leak detection: three ways to characterize the source.
}

\author{
GUILLAUME BERTHE ${ }^{1}$, PHILIPP SCHIFFMANN ${ }^{1}$, MONGI \\ BEN GAID $^{1}$
}

${ }^{1}$ IFPEN 1 à 4 avenue de Bois-Préaux 92852 Rueil-Malmaison guillaume.berthe@ifpen.fr

philipp.schiffmann@ifpen.fr, mongi.ben-gaid@ifpen.fr

In the context of global warming, each natural or industrial release of methane $\left(\mathrm{CH}_{4}\right)$ has to be monitored, localized and quantified. IFPEN develops a mobile station composed by an electric car with a pump allowing gas sampling at 2.5 and 0.5 meter from the ground level. This mobile device contains several sensors such as Picarro G2201-I analyzer, GPS and meteorological stations, an Elements'atmo UV spectrometer, a computer and a real-time visualization software. The whole gas sampling material (such as tedlar bags, drill, pump) is also brought to complete on-site measurements with further laboratory tests.

Methane (C1), ethane ( $\mathrm{C} 2)$, carbon dioxide, water vapor and $\delta^{13} \mathrm{C}$ in $\mathrm{C} 1$ molecules are recorded by the Picarro. The Elements'atmo UV spectrometer is mainly dedicated to detect odorous tetrahydrothiophene (THT) and mercaptan molecules. Both analyzers give us three clues to characterize the gas plume source highlighting by the real-time viewing software. GPS and meteorological data are useful for modeling the gas plume and finding the location of the source.

The mobile station was tested on a French gas geological storage containing both injected thermogenic methane and ethane with $\mathrm{C} 2 / \mathrm{C} 1$ ratio around $4 \%$. Results indicate that the Picarro is very useful and accurate for detecting both methane and ethane concentrations and provides the $\mathrm{C} 2 / \mathrm{C} 1$ ratio directly in the field. Anomalous methane concentrations more than five orders of atmospherical levels were clearly detected.

Isotope $\delta^{13} \mathrm{CH}_{4}$ values measured by the Picarro are also a good indicator of the methane source. However, the interpretation of $\delta^{13} \mathrm{C}$ values should be improved taking into account deuterium measurements additionally performed at the laboratory.

Finally, the elements'atmo UV spectrometer developed by IFPEN is also able to detect the mercaptan molecules at very low concentrations ( $5 \mathrm{ppb}$ ). If the THT molecule is detected, there is no doubt about a methane leak detection.

The mobile station was able to differentiate methane from a geological methane storage site than from a wild waste burial. 